The University of Maine

\title{
DigitalCommons@UMaine
}

Psychology Faculty Scholarship

Psychology

4-25-2006

\section{Focal Putamen Lesions Impair Learning in Rule- Based, but not Information-Integration Categorization Tasks}

Shawn W. Ell

University of Maine, shawn.ell@maine.edu

Natalie L. Marchant

n.marchant@ucl.ac.uk

Richard B. Ivry

ivry@berkeley.edu

Follow this and additional works at: https://digitalcommons.library.umaine.edu/psy_facpub

Part of the Cognitive Neuroscience Commons, and the Cognitive Psychology Commons

\section{Repository Citation}

Ell, Shawn W.; Marchant, Natalie L.; and Ivry, Richard B., "Focal Putamen Lesions Impair Learning in Rule-Based, but not Information-Integration Categorization Tasks" (2006). Psychology Faculty Scholarship. 28.

https://digitalcommons.library.umaine.edu/psy_facpub/28 


\title{
Focal Putamen Lesions Impair Learning in Rule-Based, but not Information-Integration Categorization Tasks
}

\author{
Shawn W. Ell, Natalie L. Marchant, Richard B. Ivry
}

\begin{abstract}
Previous research on the role of the basal ganglia in category learning has focused on patients with Parkinson's and Huntington's Disease, neurodegenerative diseases frequently accompanied by additional cortical pathology. The goal of the present study was to extend this work to patients with basal ganglia lesions due to stroke, asking if similar changes in performance would be observed in patients with more focal pathology. Patients with basal ganglia lesions centered in the putamen (6 left side, 1 right side) were tested on rule-based and information-integration visual categorization tasks. In rule-based tasks, it is assumed that participants can learn the category structures through an explicit reasoning process. In information-integration tasks, optimal performance requires the integration of information from two or more stimulus components, and participants are typically unaware of the category rules. Consistent with previous studies involving patients with degenerative disorders of the basal ganglia, the stroke patients were impaired on the rule-based task, and quantitative, model-based analyses indicate that this deficit was due to the inefficient application of decision strategies. In contrast, the patients were unimpaired on the information-integration task. This pattern of results provides converging evidence supporting a role of the basal ganglia and, in particular, the putamen in rule-based category learning.
\end{abstract}

Keywords: Basal ganglia, neostriatum, strategy, explicit, implicit

\section{Introduction}

Category learning has been one of the cornerstone areas of study in cognitive psychology. With the emergence of cognitive neuroscience, the neural substrates of this ability have received much attention over the past decade (see Ashby \& Spiering, 2004; Keri, 2003 for reviews). The basal ganglia have been a focal point of inquiry in this research, behaviorally (e.g., Knowlton, Mangels, \& Squire, 1996; Shohamy, Myers, Onlaor, \& Gluck, 2004), computationally (Ashby, Alfonso-Reese, Turken, \& Waldron, 1998; Brown, Bullock, \& Grossberg, 1999; Frank, 2005), and in neuroimaging studies (Poldrack et al., 2001; Seger \& Cincotta, 2002). To date, neuropsychological studies of the role of the basal ganglia in category learning have focused on patients with degenerative disorders of the basal ganglia, and in particular, patients with Parkinson's disease. In the current study, we extend this work by testing patients with focal lesions of the basal ganglia due to stroke.

Testing patients with focal lesions has several advantages compared to those with degenerative disorders. First, unlike Parkinson patients, dopaminergic projections to prefrontal cortex are likely to be normal as long as the lesion excludes the substantia nigra pars compacta, ventral tegmental area, and internal capsule. Second, patients with focal lesions offer a better opportunity to relate structure to function in that one can ask if observed deficits are related to the site of the lesion. Third, they provide an opportunity to evaluate if deficits require bilateral basal ganglia pathology. 
An additional goal of the present study is to determine whether focal basal ganglia lesions affect learning in both rule-based and information-integration category learning tasks (Ashby \& Ell, 2001). Rule-based tasks are those in which the categories can be learned by an explicit reasoning process. Frequently, the rule that maximizes accuracy (i.e., the optimal rule) can easily be described verbally (Ashby et al., 1998). In many applications, only one stimulus dimension is relevant (e.g., line length), and the participant's task is to identify the relevant dimension and then map the different dimensional values to the relevant categories. Rule-based tasks are assumed to be learned via a hypothesis-testing process that is dependent on working memory and executive functions (Ashby et al., 1998). Indeed, the Wisconsin Card Sorting task, one of the standard tools for assessing executive function, is in essence a rule-based categorization task.

In contrast, information-integration tasks are those in which accuracy is maximized when information from two or more dimensions (e.g., line length and orientation) is integrated at some pre-decisional stage (Ashby et al., 1998). The type of integration required could take any number of forms, from a weighted combination of the two dimensions (Ashby \& Gott, 1988; Garner, 1974) to more holistic processing (e.g., Kemler Nelson, 1993) to the incremental acquisition of stimulus-response associations (Ashby \& Waldron, 1999), but the critical point is that integration occurs prior to any decision processes (Ashby et al., 1998). Unlike rule-based tasks, participants have difficulty verbalizing the optimal decision strategy in information-integration tasks, despite being able to successfully learn the categories (Ashby et al., 1998).

Behavioral evidence suggests that qualitatively different systems are engaged during category learning in rule-based and information-integration tasks (see Ashby \& Maddox, 2005; Maddox \& Ashby, 2004 for reviews). Learning in information-integration tasks is more sensitive to the timing (Maddox, Ashby, \& Bohil, 2003) and nature of trial-bytrial feedback (Ashby, Maddox, \& Bohil, 2002), and more closely linked to motor systems (Ashby, Ell, \& Waldron, 2003). Rulebased tasks are more sensitive to dual task interference (Waldron \& Ashby, 2001; Zeithamova \& Maddox, in press) and other manipulations designed to tax working memory (Maddox, Filoteo, Hejl, \& Ing, 2004).

In contrast to the wealth of behavioral data comparing rule-based and informationintegration tasks, there is a paucity of studies investigating the neural substrates of these two tasks. The available neuroimaging data suggest that activity in the basal ganglia is correlated with learning in both tasks (Filoteo, Maddox, Simmons et al., 2005; Nomura et al., in press; Seger \& Cincotta, 2002). For instance, Nomura and colleagues observed that successful categorization (i.e., correct incorrect trials) was correlated with activity in the right body of the caudate nucleus in a rulebased task and bilateral activity in the body and tail of the caudate in an informationintegration task.

The role of the basal ganglia in categorization has been the focus of several neuropsychological studies. Patients with Parkinson's disease have consistently been found to be impaired on rule-based tasks (Brown \& Marsden, 1988; Cools, van den Bercken, Horstink, van Spaendonck, \& Berger, 1984; Downes et al., 1989; Maddox, Aparicio, Marchant, \& Ivry, 2005). Interestingly, these studies have all used tasks that required selective attention to a single stimulus dimension in order to maximize accuracy. At least for Parkinson's patients, this detail may be critical as the degree of their impairment increases with the number of irrelevant dimensions (Filoteo, Maddox, Ing, Zizak, \& Song, 2005). Moreover, no 
impairment was observed on a rule-based task that required the participants to attend to all stimulus dimensions (Filoteo, Maddox, Ing, \& Song, 2005; Maddox \& Filoteo, 2001).

Patients with degenerative disorders of the basal ganglia have been found to be impaired on information-integration tasks as well (Filoteo, Maddox, \& Davis, 2001; Filoteo, Maddox, Salmon, \& Song, 2005). The information-integration tasks used in these studies comprised two categories and either required the linear or nonlinear integration of the stimulus dimensions. Filoteo et al. (Filoteo, Maddox, Salmon et al., 2005; see also Maddox \& Filoteo, 2001) reported an intriguing dissociation in that Parkinson's patients were only impaired on an information-integration task involving a nonlinear decision bound. However, patients with Huntington's disease were impaired in both the linear and nonlinear cases, although the former deficit was limited to the initial training blocks (Filoteo et al., 2001).

Two studies have investigated rule-based and information-integration category learning in the same sample of patients. Ashby and colleagues (Ashby, Noble, Filoteo, Waldron, \& Ell, 2003) compared the performance of patients with Parkinson's disease to control participants on rule-based and informationintegration tasks. The stimuli comprised four binary-valued dimensions. For successful performance on the rule-based task, participants had to attend to a single relevant dimension and ignore three irrelevant dimensions. Conversely, on the informationintegration task, participants had to attend to three dimensions and ignore a single irrelevant dimension. Parkinson's patients were selectively impaired on the rule-based task. Surprisingly, when rule-based and information-integration tasks were equated for the number of relevant dimensions, Parkinson's patients were unimpaired in both tasks (Filoteo, Maddox, Ing, \& Song, 2005).
To our knowledge, only one study has investigated the impact of a focal basal ganglia lesion on category learning (Keri et al., 2002). Compared to a group of control participants, a patient with a lesion of the right neostriatum (i.e., caudate and putamen) was impaired on a probabilistic classification task (i.e., the weather prediction task, Knowlton, Squire, \& Gluck, 1994) . This task is typically considered a type of an informationintegration task given that optimal performance requires integrating information from four cues (Ashby \& Ell, 2001). However, analyses of individual differences suggests that participants frequently rely upon unidimensional rule-based strategies and memorization (Gluck, Shohamy, \& Myers, 2002).

In sum, while the neuropsychological studies indicate that degenerative disorders of the basal ganglia impair category learning, it remains unclear if this deficit extends to both rule-based and information-integration tasks. One problem in comparing performance on rule-based and information-integration tasks is that they frequently differ in terms of difficulty, optimal accuracy, and/or the number of relevant dimensions. Moreover, the literature indicates that various factors influence the degree of the observed impairments even within these two broad classes.

In the current study, we test a group of patients with focal basal ganglia lesions on the rule-based and information-integration categorization tasks introduced by Maddox et al. (2004). The stimuli were lines that varied in length and orientation, assigned to one of four categories (Figure 1). We selected stimulus sets such that the two tasks were equated on task difficulty, optimal accuracy, and the number of relevant dimensions (Maddox, Filoteo et al., 2004). For both tasks, participants should attend to both length and orientation. Optimal performance on the rulebased task requires that the participants adopt 


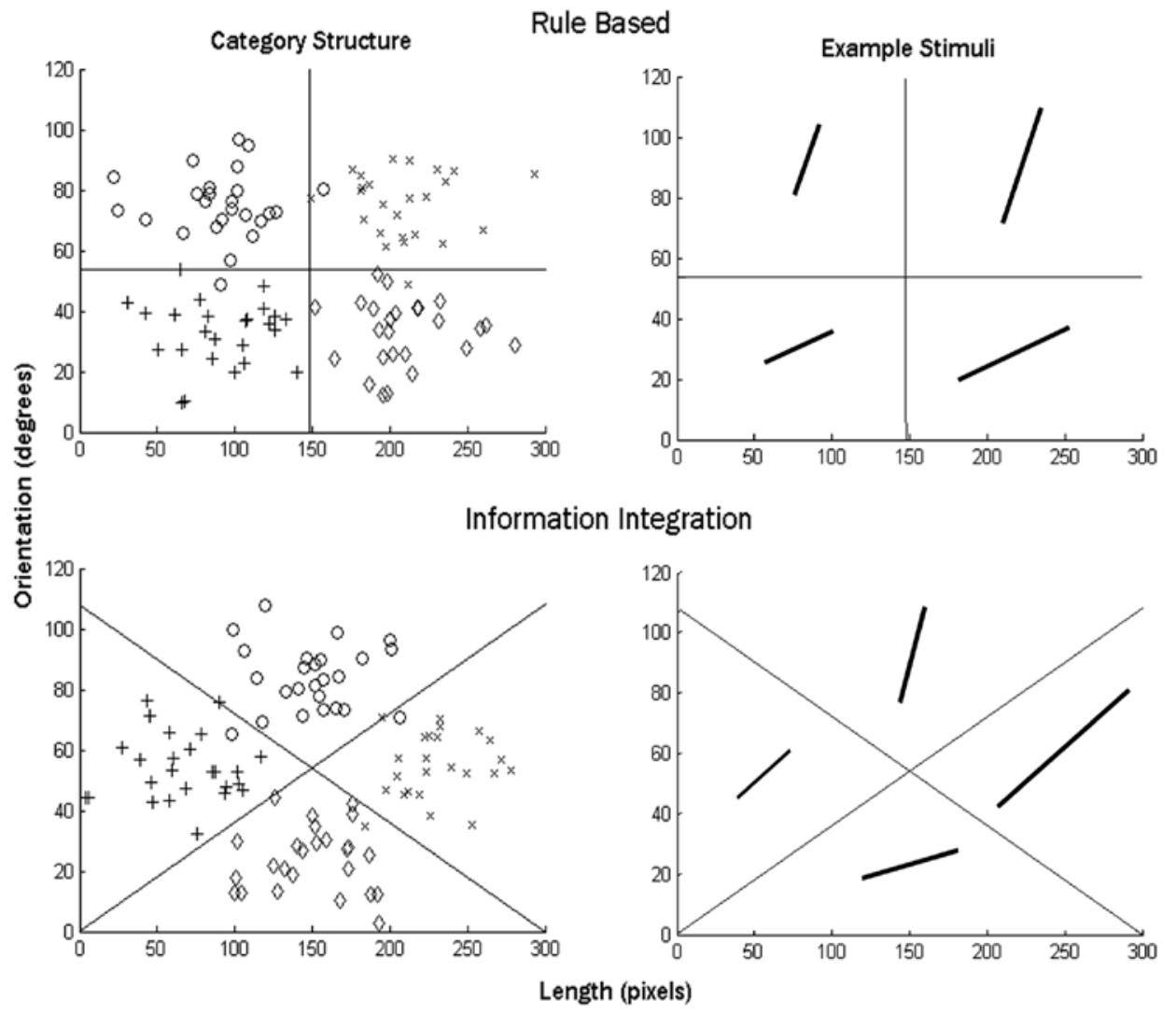

Figure 1. Scatterplot of the stimuli in length-orientation space in the two tasks (left panels) along with example stimuli (right panels). Each point in the scatterplot represents a single stimulus. Category 1 exemplars are plotted as plus signs, Category 2 exemplars as circles, Category 3 exemplars as diamonds, and Category 4 as x's. The solid lines are the optimal decision boundaries.

a conjunction strategy that involves a twostage decision process (Ashby \& Gott, 1988; Shaw, 1982). First, separate decisions should be made about the value of the stimulus on length and orientation (e.g., "Is the line short or long?”; "Is the line shallow or steep?”). Second, the outputs of the first stage decision process should be combined to make a categorization decision (e.g., "If the line is short and shallow, respond 1"; "If the line is short and steep; respond 2"; etc ...) - that is, the integration of length and orientation is post-decisional. Similar to rule-based tasks used in previous work (e.g., Ashby et al., 1998), it has been argued that the optimal decision rule can be easily verbalized (Maddox, Filoteo et al., 2004).

For the information-integration task, the categories were created by rotating the rulebased categories 45 degrees counterclockwise. Optimal performance in this task requires the integration of length and orientation information. The strategies that maximize accuracy in the information-integration task assume that integration occurs prior to making a categorization decision - that is, the integration is pre-decisional (Ashby et al., 1998; Ashby \& Gott, 1988; Maddox, Filoteo et al., 2004) ${ }^{1}$. That is not to say that rule-based

\footnotetext{
${ }^{1}$ Note that we are using a more restricted definition of a rule than is common in the psychological literature (e.g., see Bunge, 2004). Specifically, we use the term rule to refer to an explicit reasoning process. Such a definition places no limit on the complexity of a rule (e.g., the number of "and" and "or" operators in a logical expression
} 
strategies are never used in informationintegration tasks. Indeed, rule-based strategies, such as the conjunction rule shown in the top half of Figure 1, are often used early in training with information-integration tasks. Performance with such rule-based strategies is non-optimal and, over time, most participants shift to an information-integration strategy (e.g., Ell \& Ashby, in press). The latter do not lend themselves to a simple and coherent verbal description (Maddox, Filoteo et al., 2004).

\section{Method}

\section{Participants and Design}

Seven patients (one female) with unilateral damage to the basal ganglia resulting from stroke were recruited for this experiment. The patients were recruited from the VA Medical Center in Martinez, CA. The lesion was restricted to the left side for six of the patients and to the right side in the other patient. The greater representation of patients with leftsided damage was due to the fact that some referrals came from a speech rehabilitation clinic.

Lesion reconstructions for six of the patients are presented in Figure 2. The pathology was centered in the basal ganglia, with evidence of putamen involvement in all seven patients. The lesion extended into the caudate for one patient, BG01. There was evidence that the lesions also extended into white matter (internal, external, and extreme capsules) for some patients and may have

of the rule). Nonetheless, it is reasonable to assume that as complexity increases, the salience of a rule will decrease (Alfonso-

Reese, 1997) as will the likelihood that participants will use an explicit reasoning process (Ashby et al., 1998). To be certain, the boundary conditions on what exactly constitutes a rule are fuzzy. However, our claim that conjunction strategies involve an explicit reasoning process is consistent with previous work (Ashby \& Gott, 1988; Maddox, Filoteo et al., 2004; Salatas \& Bourne, 1974; Shaw, 1982; Shepard, Hovland, \& Jenkins, 1961). Importantly, recent evidence supports the distinction we make between conjunction strategies and information-integration strategies (Filoteo, Maddox, Ing, \& Song, 2005; Maddox, Bohil, \& Ing, 2004; Zeithamova \& Maddox, in press). included insular cortex for one patient (BG11). Patient BG09 displayed slight cerebellar atrophy. We decided to include this patient in the basal ganglia group because previous research has shown that, across a variety of tasks, patients with cerebellar lesions are unimpaired in category learning (Ell \& Ivry, 2005; Maddox et al., 2005; Witt, Nuhsman, \& Deuschl, 2002). Thus, any impairment in this patient's performance is unlikely to result from the cerebellar atrophy. Based on medical histories, patients BG01 and BG12 may have experienced an additional stroke in the thalamic region. However, these lesions were contiguous with damage from the basal ganglia strokes. We opted to include these patients in the study.

Nine (four female) control participants were recruited from the Berkeley community. The controls were screened for the presence of a neurological disorder or a history of psychiatric illness and selected to span the range of the patients in terms of age, education, and IQ. Demographic information for the patients and controls is provided in Table 1. Basal ganglia and control groups were reasonably matched on age $[t(14)=1.0$, $p=.4]$ and education $[t(14)=-.4, p=.7]$. All participants reported $20 / 20$ vision or vision corrected to 20/20.

The participants were tested on the rulebased and information-integration tasks in two different sessions. The sessions were separated by a minimum of 1 week to minimize interference between the two tasks. Each session lasted approximately 2 hours, including an hour of neuropsychological testing. The order of the categorization tasks between sessions and the order of the withinsession tasks (categorization and neuropsychological assessment) were counterbalanced across participants. Participants were monetarily compensated.

The study protocol was approved by the institutional review boards of the VA Medical 


\section{PUTAMEN AND CATEGORY LEARNING}

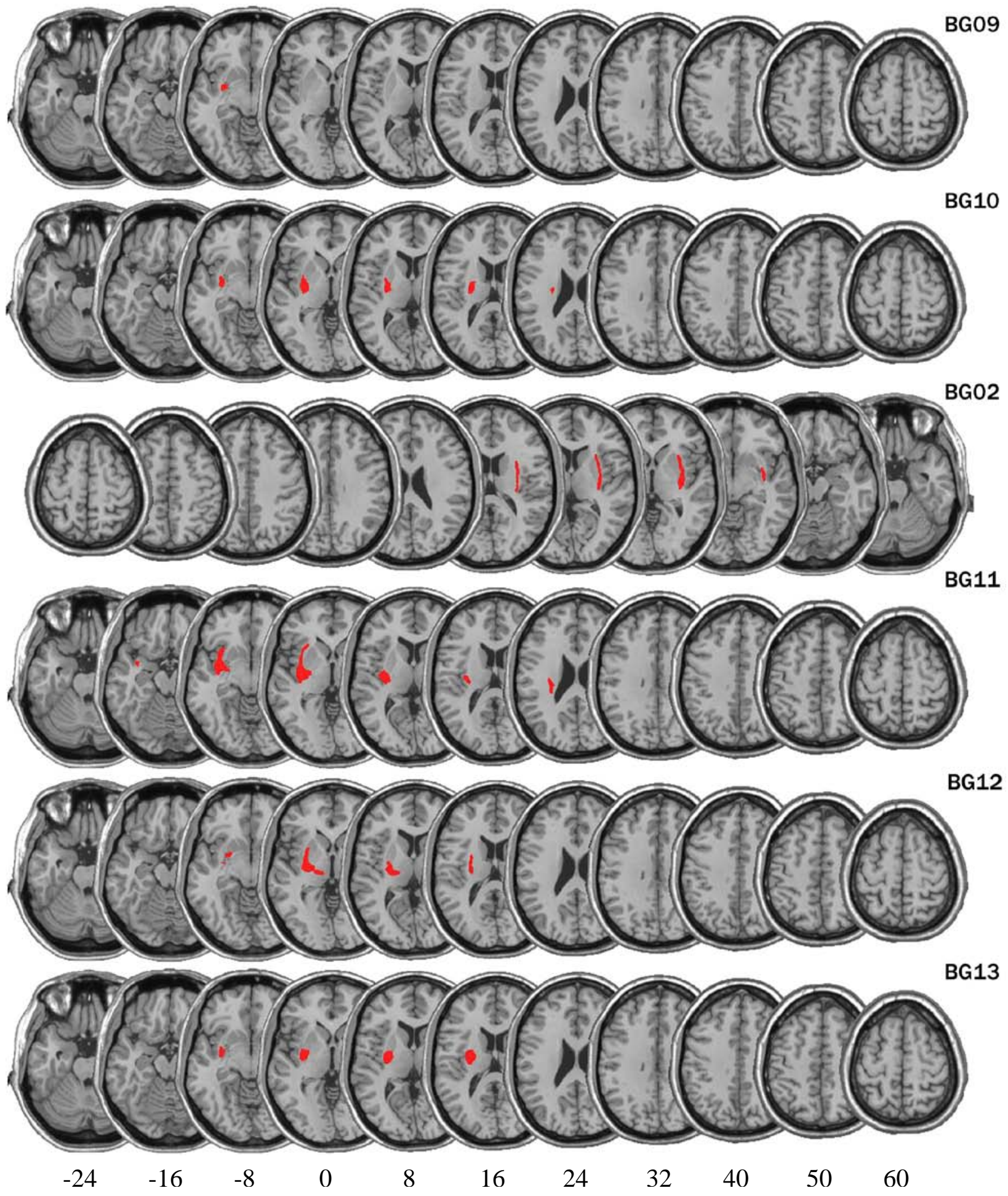

Figure 2. Lesion reconstruction (in white) for six of the patients with lesions of the basal ganglia, presented on 11 axial slices corresponding to Talairach coordinates of -24, -16, -8, 0, 8, 16, 24, 32, 40, 50, and $60 \mathrm{~mm}$. The striatum (putamen and caudate) is present in sections -8 through 24; the globus pallidus in sections -8 through 16 . Figures were generated with the MRIcro software package (Rorden \& Brett, 2000) using procedures described in (Brett et al., 2001). We were unable to obtain access to a digital copy of the scan for one patient, BG01. BG - basal ganglia patients. 
PUTAMEN AND CATEGORY LEARNING

Table 1. Participant Demographic Information

\begin{tabular}{cccccccc}
\hline \multicolumn{4}{c}{ Basal Ganglia Patients } & & \multicolumn{3}{c}{ Control Participants } \\
ID & $\begin{array}{c}\text { Age at } \\
\text { Test }\end{array}$ & ED & $\begin{array}{c}\text { Lesion } \\
\text { Hemisphere }\end{array}$ & $\begin{array}{c}\text { Year of } \\
\text { Stroke }\end{array}$ & ID & $\begin{array}{c}\text { Age at } \\
\text { Test }\end{array}$ & ED \\
\hline BG09 & 56 & 13 & Left & 1997 & MP04 & 57 & 17 \\
BG10 & 68 & 13 & Left & 1994 & MP03 & 54 & 14 \\
BG01 & 80 & 14 & Left & $1974 \&$ & MP15 & 59 & 16 \\
BG02 & 54 & 16 & Right & 2001 & MP05 & 50 & 12 \\
BG11 & 46 & 8 & Left & 2002 & MP11 & 53 & 13 \\
BG12 & 55 & 17 & Left & $1992 \&$ & MP30 & 58 & 14 \\
BG13 & 63 & 14 & Left & 2002 & OP30 & 65 & 12 \\
& & & & & OP31 & 63 & 17 \\
& & & & & MP10 & 46 & 12 \\
\hline Mean & 60.3 & 13.6 & & & Mean & 56.1 & 14.1 \\
SD & 11.2 & 2.9 & & & SD & 6.1 & 2.1 \\
\hline
\end{tabular}

Note. ID - participant identification code; BG - basal ganglia patients; MP - middle-aged participants; OP - older participants ED - years of education.

Center in Martinez and University of California, Berkeley.

\section{Neuropsychological Assessment}

A battery of neuropsychological tests was used to assess different aspects of cognitive function in both patients and controls. The Mini Mental State Exam (MMSE) was used to screen for dementia. Subtests of the Wechsler Adult Intelligence Scale - Third Edition (WAIS-III, Wechsler, 1997) were used to calculate verbal IQ, performance IQ, and full scale IQ. Standardized scores from the Vocabulary, Similarities, Arithmetic, Digit Span, and Information WAIS-III subtests generated a prorated verbal IQ. Standardized scores from the Picture Completion, Matrix Reasoning, Picture Arrangement, Symbol Search WAIS-III subtests generated a prorated performance IQ. Verbal learning and memory was assessed using the California Verbal Learning Test (CVLT, Delis, Kramer, Kaplan, \& Ober, 1984). The CVLT includes an initial learning phase comprising a 16 item word list (repeated over 5 blocks). Recall and recognition memory were subsequently probed following a delay.

In rule-based tasks (and possibly to a lesser extent in information-integration tasks), learning is assumed to be highly dependent upon working memory and executive processes (see Ashby et al., 1998; Ashby \& Maddox, 2005 for reviews). Thus, neuropsychological tests were included to assess these functions. Standardized scores from the Digit Span, Arithmetic, and LetterNumber Sequencing subtests provided a working memory index. Language production and executive abilities were assessed using the verbal fluency subtest from the Delis-Kaplan Executive Function System (D-KEFS - Delis, Kaplan, \& Kramer, 2001) which includes phonemic, semantic, and a more complex semantic switching task. We did not include a specific test for aphasia. Some of the patients had been treated in a speech and language clinic prior to their referral to our study (and thus, the greater representation of patients with left-sided lesions). However, informal observation indicated that none of the patients demonstrated overt aphasic problems, and all 
were able to readily understand the task instructions. As assessed by the Beck Depression Inventory ( $2^{\text {nd }}$ Ed.) (BDI - Beck, Steer, \& Brown, 1996), none of the patients or control participants was found to have symptoms of clinical depression.

\section{Stimuli and Stimulus Generation}

One-hundred stimuli were used in the rulebased or information-integration tasks, with 25 assigned to each of the four response categories (see Figure 1). To create these structures, we used the randomization technique introduced by Ashby and Gott (1988) in which each category was defined as a bivariate normal distribution with a mean and a variance on each dimension, and by a covariance between dimensions. The exact parameter values were taken from Maddox et al. (2004). Random samples $(x, y)$ were drawn from the distribution for one of the four categories, and these values were used to construct lines of length $x$ pixels and orientation $y \times(\pi / 500)$ radians. The scale factor $(\pi / 500)$ was selected based upon past research in an effort to equate the discriminability of changes in perceived length to changes in perceived orientation. The information-integration category structure was generated by rotating the rule-based category structure 45 degrees clockwise around a central point located at 150 pixels in length (4 degrees of visual angle) and 150 orientation units (i.e., 54 degrees from horizontal). Twenty-five stimuli were randomly sampled, from each of the four category distributions to select the set of 100 stimuli for each task. A linear transformation was performed to ensure that the sample and population means, variances, and covariances were identical. The order of the resulting 100 stimuli was randomized separately for each block and each participant.

Each stimulus was presented on a black background and subtended a visual angle ranging from 0.7 to 7.3 degrees at a viewing distance of approximately $60 \mathrm{~cm}$. The stimuli were generated and presented using the Psychophysics Toolbox extensions for MATLAB (Brainard, 1997; Pelli, 1997). The stimuli were displayed on either a 15" CRT with $1024 \times 768$ pixel resolution in a dimly lit room or on a laptop LCD of the same resolution when patients were tested in their home. The length of the stimuli were scaled to equate the range of visual angles in the present experiment to those used by Maddox et al. (2004).

\section{Procedure}

On each trial, a single stimulus was presented and the participant was instructed to make a category assignment by pressing one of four response keys with either index finger. The instructions emphasized accuracy and there was no response time limit. After responding, feedback regarding the correctness of the response (correct: green cross; incorrect: red cross) along with the correct category label was presented in the center of the screen for $1 \mathrm{~s}$. The screen was then blanked for $500 \mathrm{~ms}$ prior to the appearance of the next stimulus. In addition to trial-by-trial feedback, feedback was given at the end of each block of 100 trials regarding the participant's accuracy during that block. The participant was told that there were four equally likely categories and informed that the best possible accuracy was $95 \%$ (i.e., optimal accuracy).

A standard keyboard was used to collect responses. The keyboard characters ' $z$ ', 'w', '/, and 'p' were assigned to categories 1-4, respectively. Following, Maddox et al.(2004), the category numbers did not appear on the response keys and the response mappings were fixed across participants. Great care was taken to instruct the participants as to the category-response key mappings.

Each participant completed one practice and five test blocks of 100 trials for each task. Within each block, the ordering of the 100 
stimuli was randomized. The experimenter closely monitored performance during the practice block, repeating the instructions as needed and providing encouragement. When necessary, the experimenter would remind the participants of the category - response key mappings during the practice block. All participants were able to accurately produce the category - response key mappings by the end of the practice block. They then completed the five test blocks without further interruption other than a brief break between blocks.

We requested that participants respond using both hands (left hand for the ' $z$ ' and ' $w$ ' keys and right hand for the '/' and 'p' keys). We did not expect performance to vary between the two hands given that the response requirements were minimal (e.g., speed was not emphasized) and that patients with chronic focal basal ganglia lesions show little evidence of motor impairment (e.g., Aparicio, Diedrichsen, \& Ivry, 2005). Indeed, error rates did not differ as a function of the hand used to respond in the current study. One participant (BG10) reported discomfort in using his contralesional hand and thus made all responses with the ipsilesional hand.

\section{Results and Discussion}

\section{Accuracy-Based Analyses}

Inspection of the learning curves suggests that the basal ganglia patients were impaired on the rule-based task, but not on the information-integration task (Figure 3). Interestingly, this impairment appeared to be limited to early in training. These observations were confirmed by separate 5 block $\mathrm{x} 2$ group mixed ANOVAs. In the rule-based task, the main effect of block was significant $[F(4,56)$ $\left.=53.34, p<.001, M S E=25.95, \eta_{p}{ }^{2}=.79\right]$, but this was qualified by a significant block $\mathrm{x}$ group interaction $[F(4,56)=7.31, p<.001$, $\left.M S E=25.95, \eta_{p}{ }^{2}=.34\right]$. The main effect of group was not significant $[F(1,14)=1.68, p$ $\left.=.22, M S E=1301.82, \eta_{p}{ }^{2}=.11\right]$. Pairwise comparisons revealed that the interaction was driven by accuracy rates in the basal ganglia group that were significantly lower than the control group during block $1(p=.03)$ and marginally significant during block 2 ( $p=$ .08). None of the remaining pairwise comparisons were significant (block 3: $p=$ .40 ; block 4: $p=.53$; block 5: $p=.63$ ).

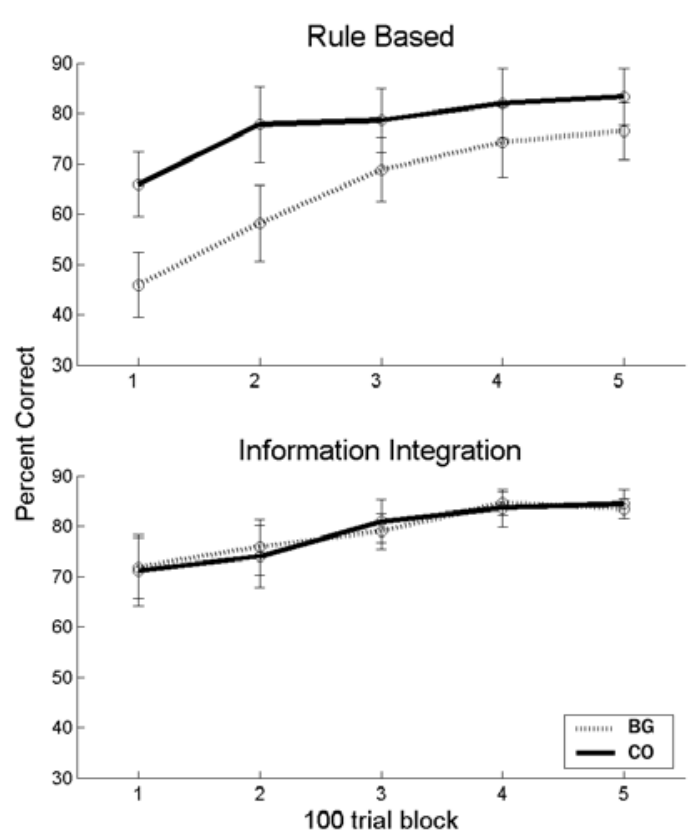

Figure 3. Average accuracy (+/- SEM) in the rulebased and information-integration tasks. BG basal ganglia patients; $\mathrm{CO}$ - control participants.

The individual accuracy rates from blocks 1 and 2 of the rule-based task are given in Table 2. With chance performance at 25\%, it is evident that some learning had occurred by the end of the first block. Three of the seven patients were responding correctly on at least half of the trials; the same was true for seven of the nine control participants. While there is considerable overlap between the two distributions, five of the patients performed below the mean of the control group across blocks 1 and 2. 
Table 2

Neuropsychological Assessment

\begin{tabular}{|c|c|c|c|c|c|c|c|c|c|c|c|c|c|c|}
\hline \multirow[b]{2}{*}{ ID } & \multirow[b]{2}{*}{ MMSE } & \multirow[b]{2}{*}{ VIQ } & \multicolumn{3}{|c|}{ WAIS-III } & \multicolumn{4}{|c|}{ D-KEFS } & \multicolumn{3}{|c|}{ CVLT } & \multicolumn{2}{|c|}{$\begin{array}{c}\text { Accuracy in RB } \\
\text { task }\end{array}$} \\
\hline & & & PIQ & FSIQ & $\begin{array}{l}\text { WM } \\
\text { Index }\end{array}$ & $\begin{array}{l}\text { Letter } \\
\text { Fluency } \\
\text { CR }\end{array}$ & $\begin{array}{c}\text { Category } \\
\text { Fluency } \\
\text { CR }\end{array}$ & $\begin{array}{l}\text { Switching } \\
\text { Fluency } \\
\text { CR }\end{array}$ & $\begin{array}{l}\text { Number } \\
\text { of Correct } \\
\text { Switches }\end{array}$ & $\begin{array}{l}\text { CR During } \\
\text { Learning } \\
\text { (raw score/80) }\end{array}$ & $\begin{array}{l}\text { Long Delay } \\
\text { Free Recall }\end{array}$ & $\begin{array}{c}\text { Recognition } \\
\text { Discriminability } \\
\text { Index }\end{array}$ & Block 1 & Block 2 \\
\hline \multicolumn{15}{|c|}{ Basal Ganglia Patients } \\
\hline BG09 & 29 & 105 & 99 & 103 & 88 & 26 & 37 & 12 & 11 & 42 & 13 & 3.4 & 27.3 & 39.0 \\
\hline BG10 & 28 & 119 & 107 & 115 & 113 & --- & --- & --- & --- & 36 & 7 & 2.9 & 69.0 & 77.0 \\
\hline BG01 & 28 & 116 & 114 & 116 & 109 & 36 & 23 & 14 & 12 & 40 & 13 & 3.7 & 35.0 & 47.0 \\
\hline BG02 & 28 & 117 & 98 & 109 & 111 & 37 & 31 & 15 & 14 & 40 & 6 & 1.8 & 43.0 & 66.0 \\
\hline BG11 & 29 & 75 & 79 & 80 & 80 & 27 & 34 & 7 & 5 & 36 & 7 & 2.3 & 28.9 & 32.0 \\
\hline BG12 & 29 & 111 & 117 & 114 & 94 & 30 & 36 & 17 & 15 & 56 & 13 & 3.7 & 53.0 & 60.0 \\
\hline BG13 & 29 & 111 & 97 & 104 & 97 & 33 & 33 & 12 & 12 & 27 & 10 & 3.1 & 65.0 & 86.0 \\
\hline Mean & 28.6 & 107.7 & 101.6 & 105.9 & 98.9 & 31.5 & 32.3 & 12.8 & 11.5 & 39.6 & 9.9 & 3.0 & 45.9 & 58.1 \\
\hline$S D$ & .5 & 15.2 & 12.7 & 12.5 & 12.6 & 4.6 & 5.1 & 3.4 & 3.5 & 8.8 & 3.2 & 0.7 & 16.9 & 19.9 \\
\hline MP04 & 30 & 143 & 117 & 135 & 136 & 56 & 44 & 15 & 14 & --- & --- & --- & 77.0 & 92.0 \\
\hline MP03 & 30 & 119 & 105 & 113 & 117 & 37 & 37 & 14 & 13 & 60 & 15 & 3.70 & 85.0 & 91.0 \\
\hline MP15 & 30 & 119 & 130 & 127 & 111 & 53 & 44 & 19 & 18 & --- & --- & --- & 85.0 & 94.0 \\
\hline MP05 & 30 & 117 & 127 & 123 & 109 & 65 & 67 & 17 & 15 & 64 & 13 & 3.70 & 64.0 & 82.0 \\
\hline MP11 & 26 & 113 & 105 & 110 & 99 & 71 & 49 & 12 & 13 & 53 & 14 & 3.70 & 48.0 & 55.0 \\
\hline MP30 & 30 & 133 & 127 & 134 & 117 & 63 & 57 & 14 & 12 & 44 & 11 & 2.70 & 59.0 & 68.0 \\
\hline OP30 & 29 & 104 & 105 & 104 & 102 & 49 & 42 & 16 & 15 & 35 & 7 & 2.80 & 43.0 & 47.0 \\
\hline OP31 & 29 & 124 & 94 & 111 & 108 & --- & --- & --- & --- & 44 & 10 & 3.00 & 68.0 & 79.0 \\
\hline MP10 & 28 & 72 & 76 & 72 & 90 & 42 & 37 & 13 & 10 & 45 & 7 & 2.20 & 54.0 & 69.7 \\
\hline Mean & 29.1 & 116.0 & 110.0 & 114.3 & 110.0 & 54.5 & 47.1 & 15.0 & 13.8 & 49.3 & 11.0 & 3.1 & 64.8 & 75.3 \\
\hline$S D$ & 1.4 & 20.0 & 17.7 & 19.3 & 13.1 & 11.7 & 10.3 & 2.3 & 2.4 & 10.2 & 3.2 & 0.6 & 17.1 & 19.1 \\
\hline$t$ & -1.0 & -0.9 & -1.0 & -1.0 & -1.7 & -4.5 & -3.2 & -1.4 & -1.4 & -1.9 & -.67 & -.4 & & \\
\hline$p$ & 0.3 & 0.4 & 0.3 & 0.3 & 0.1 & $.001 *$ & $.008 *$ & 0.2 & 0.2 & .08 & .52 & .7 & & \\
\hline
\end{tabular}

Note. ID - participant identification code; BG - basal ganglia patients; MP - middle-aged participants; OP - older participants; MMSE = Mini Mental State Exam; WAIS-III - Wechsler Adult Intelligence Scale III; VIQ - Verbal IQ; PIQ - Performance IQ; FSIQ - Full-Scale IQ; D-KEFS - Delis-Kaplan Executive Functioning System; CR - correct responses; CVLT - California Verbal Learning Test; RB - rule based. All t-tests computed as BG-CO. * - significant difference between BG and CO groups at $p=.05$. 
In the information-integration task, the main effect of block was significant $[F(4,56)$ $\left.=11.70, p<.001, M S E=41.89, \eta_{p}{ }^{2}=.46\right]$. However, neither the block $x$ group interaction $\left[F(4,56)=.23, p=.92, M S E=41.89, \eta_{p}{ }^{2}=\right.$ .02] nor the main effect of group $[F(1,14)=$ $0, p=.99, M S E=763.06, \eta_{p}{ }^{2}=0$ ] were significant. $^{2}$ Post-hoc analyses revealed that accuracy significantly increased from block 1 to block $2(p=.02)$, block 2 to block $3(p=$ $.02)$, block 3 to block $4(p=.01)$, but not from block 4 to block $5(p=.88)$.

One possible explanation for the selective impairment in the rule-based task is that it was simply more difficult than the informationintegration task. To address this question, a 5 block $\times 2$ task repeated measures ANOVA was conducted on the data from the control participants. The main effect of block was significant $[F(4,32)=24.89, p<.001, M S E=$ 25.43, $\left.\eta_{p}{ }^{2}=.76\right]$. Importantly, neither the main effect of task $[F(1,8)=1.95, p<.20$, $\left.M S E=150.75, \eta_{p}{ }^{2}=.20\right]$ nor the block x task interaction $[F(4,32)=.97, p=.44, M S E=$ $\left.40.20, \eta_{p}{ }^{2}=.11\right]$ were significant. Thus, while based on a null result, the results from the control participants indicate that the tasks were of comparable difficulty.

\section{Relationship between Accuracy on} Categorization Tasks and Demographic, Neuropsychological, and Neuropathological Variables

As shown in Table 2, the groups were within one standard deviation of each other on most of the neuropsychological assessments. In general, there was a trend for the patients to perform worse on the CVLT, working memory, and executive function assessments. The patients were marginally impaired in the

\footnotetext{
${ }^{2}$ We performed a more fine-grained analysis to test whether an early learning impairment on the information-integration task might be found across the 100 trials of Block 1. Repeating the ANOVAs with 25-trial mini-blocks yielded the same results as in the main analyses: The group $\mathrm{x}$ block interaction was only significant for the rule-based task.
}

learning phase of the CVLT. This difference did not extend to subsequent tests of recall and recognition. Overall, the patients' score on the working memory index was not significantly lower than the controls, but the patients were significantly worse on the Arithmetic and Letter-Number Sequencing subtests. [Arithmetic: $t(11)=-2.24, p=.05$; LetterNumber Sequencing: $t(11)=-2.7, p=.02$; Digit Span Forward: $t(11)=-.96, p=.36$; Digit Span Backward: $t(11)=-.88, p=.40$ ] Within the D-KEFS, the patients were significantly worse than control group in the letter and category fluency tasks. In general, the picture of a mild to moderate deficit in executive functioning for patients with focal basal ganglia lesions is consistent with previous assessments (Keri et al., 2002; Troyer, Black, Armilio, \& Moscovitch, 2004)

Given the individual variability in accuracy in the basal ganglia group, we asked whether any of the neuropsychological variables may be related to the observed impairment in category learning. To assess this question, accuracy on the rule-based task, averaged over blocks 1 and 2, was correlated with these variables. The same analysis was performed on the data from the control group for comparison purposes. As can be seen in Table 3, the correlations for the patients were generally positive, especially those between accuracy and measures of intelligence and executive function, although they failed to achieve standard significance levels. Interestingly, there was also a marginally significant correlation between accuracy and the working memory index for the control participants. In light of the sizeable, albeit non-significant difference between the basal ganglia and control groups on the working memory index, it is possible that a working memory deficit may underlie the impairment in the rule-based task. This analysis is far from conclusive given the inconsistent pattern of results across the various working memory 
subtests and the low reliability of these correlations due to the small sample size.

There was also considerable variability in lesion volume across participants. Therefore,

Table 3

Correlations Between Demographic and Neuropsychological Variables and Accuracy, Averaged Across Blocks 1 and 2, in the RuleBased Task.

\begin{tabular}{lcccc} 
& \multicolumn{2}{c}{ BG } & \multicolumn{2}{c}{ CO } \\
& $r$ & $p$ & $r$ & $p$ \\
\hline Age & .30 & .52 & .08 & .85 \\
ED & .47 & .29 & .65 & .06 \\
& WAIS III & & & \\
VIQ & .62 & .14 & .45 & .23 \\
PIQ & .34 & .46 & .35 & .36 \\
FSIQ & .51 & .24 & .45 & .23 \\
WM Index & .56 & .19 & .62 & .07 \\
Arithmetic & .71 & .11 & .69 & .09 \\
Letter-Number & .77 & .08 & .49 & .27 \\
Sequencing & & & & \\
Digit Span Forward & .61 & .20 & .76 & .05 \\
Digit Span Backward & .67 & .15 & .05 & .92 \\
\multicolumn{1}{c}{ DKEFS } & & & \\
Letter Fluency CR & .50 & .32 & .30 & .47 \\
Category Fluency CR & .02 & .97 & .10 & .82 \\
Switching Fluency CR & .46 & .36 & .45 & .27 \\
Number of Correct & .60 & .21 & .36 & .38
\end{tabular}

Switches

\section{CVLT}

\begin{tabular}{|c|c|c|c|}
\hline CR During Learning & $\begin{array}{l}- \\
.28\end{array}$ & .54 & .65 \\
\hline Long Delay Free Recall & $\begin{array}{c}- \\
.24\end{array}$ & .60 & .54 \\
\hline $\begin{array}{l}\text { Recognition } \\
\text { Discriminability Index }\end{array}$ & 0 & 1 & .37 \\
\hline
\end{tabular}

\begin{tabular}{llllll} 
Lesion Volume & & .05 & .92 & --- & --- \\
\hline
\end{tabular}

Note. BG - basal ganglia patients; CO - control participants; WAIS-III - Wechsler Adult Intelligence Scale III; ED - years of education; VIQ - Verbal IQ; PIQ - Performance IQ; FSIQ - Full-Scale IQ; WM working memory; D-KEFS - Delis-Kaplan Executive Functioning System; CR - correct responses; CVLT -
California Verbal Learning Test; * - significant correlation at $p=.05$

one hypothesis is that the impairment in the rule-based task may be related to the size of the pathology. However, lesion volume was not significantly correlated with accuracy in the rule-based task (see Table 3). The characteristics of our sample of patients (i.e., six individuals with lesions to the left basal ganglia and only one with a lesion to the right basal ganglia) did not permit a test of the relative importance of the left and right basal ganglia in rule-based and informationintegration category learning tasks. BG02, the one patient with a right-sided lesion performed near the basal ganglia group average during blocks 1 and 2 in the rulebased task (see Table 2) and consistently above average in the remaining blocks (block 3: 86.9; block 4: 91; block 5: 87.9).

\section{Model-Based Analyses}

The analysis of the accuracy data revealed a selective impairment of the basal ganglia patients early in performance on the rulebased task. To further explore the basis of this impairment, we now turn to model-based analyses that can evaluate different ways in which the patients might have difficulty on the rule-based task. For example, a learning impairment might result from the use of a suboptimal strategy. Alternatively, the participant might choose the correct strategy, but apply it inconsistently. The following analyses present a quantitative approach to evaluating these hypotheses.

To get a more detailed description of how participants categorized the stimuli, a number of different decision bound models (Ashby, 1992a; Maddox \& Ashby, 1993) were fit separately to the data for every participant from every block. Decision bound models are derived from general recognition theory (Ashby \& Townsend, 1986), a multivariate generalization of signal detection theory 


\begin{tabular}{|c|c|c|c|c|c|c|c|}
\hline \multicolumn{8}{|c|}{ Rule-Based Task } \\
\hline \multicolumn{4}{|c|}{ Basal Ganglia Patients (n=7) } & \multicolumn{4}{|c|}{ Controls $(n=9)$} \\
\hline \multicolumn{4}{|c|}{ \%RA } & & & \multicolumn{2}{|c|}{$\%$ RA } \\
\hline Block & \%Rule-Based & Mean & SEM & Block & $\begin{array}{c}\text { \%Rule- } \\
\text { Based }\end{array}$ & Mean & SEM \\
\hline 1 & 85.7 & 49.9 & 6.8 & 1 & 67.7 & 72.9 & 3.7 \\
\hline 2 & 71.4 & 59.9 & 8.7 & 2 & 88.9 & 76.7 & 5.5 \\
\hline 3 & 85.7 & 73.3 & 6.1 & 3 & 67.7 & 80.6 & 5.3 \\
\hline 4 & 71.4 & 78.4 & 5.0 & 4 & 88.9 & 85.2 & 4.0 \\
\hline 5 & 85.7 & 80.8 & 4.4 & 5 & 88.9 & 84.2 & 5.5 \\
\hline \multicolumn{8}{|c|}{ Information-Integration Task } \\
\hline \multicolumn{6}{|c|}{$\%$ RA } & \multicolumn{2}{|c|}{$\%$ RA } \\
\hline Block & \%Rule-Based & Mean & SEM & Block & $\begin{array}{c}\text { \%Rule- } \\
\text { Based }\end{array}$ & Mean & SEM \\
\hline 1 & 14.3 & 72.1 & 8.6 & 1 & 44.4 & 73.3 & 6.8 \\
\hline 2 & 28.6 & 70.4 & 5.8 & 2 & 33.3 & 74.2 & 6.3 \\
\hline 3 & 14.3 & 77.1 & 4.2 & 3 & 44.4 & 81.7 & 3.6 \\
\hline 4 & 0 & 85.9 & 2.5 & 4 & 33.3 & 82.0 & 5.1 \\
\hline 5 & 14.3 & 88.4 & 2.6 & 5 & 44.4 & 79.4 & 4.8 \\
\hline
\end{tabular}

Table 4

Summary of the Results of the Model-Based Analyses from the Rule-Based and InformationIntegration Tasks.

Note. \%Rule-based - percent of participants whose data were best-fit by an rule-based model; \%RA - percent of responses accounted for by the best-fitting model.

(Green \& Swets, 1966). It is assumed that, on each trial, the percept can be represented as a point in a multidimensional psychological space and that each participant partitions the perceptual space into response regions by constructing a decision bound. The participant determines which region the percept is in, and then makes the corresponding response. Despite this deterministic decision strategy, decision bound models predict probabilistic responding because of trial-by-trial perceptual and criterial noise (Ashby \& Lee, 1993).

Two different types of decision bound models were fit to each participant's responses. One type assumes that participants use a rule-based decision strategy and one type assumes an information-integration strategy (see the Appendix for details of the specific models and model fitting procedures). These models make no detailed processing assumptions in the sense that a number of different process-based accounts are compatible with each of the models (e.g., Ashby, 1992a; Ashby \& Waldron, 1999). Thus, if an information-integration model fits significantly better than a rule-based model, we can be confident that participants did not use a rule-based strategy even though we cannot specify which information-integration strategy was used. Similarly, if a rule-based model fits significantly better than the information-integration models, we gain evidence that the participant used a rule-based strategy, although we cannot rule out all information -integration strategies because some of these can mimic rule-based 


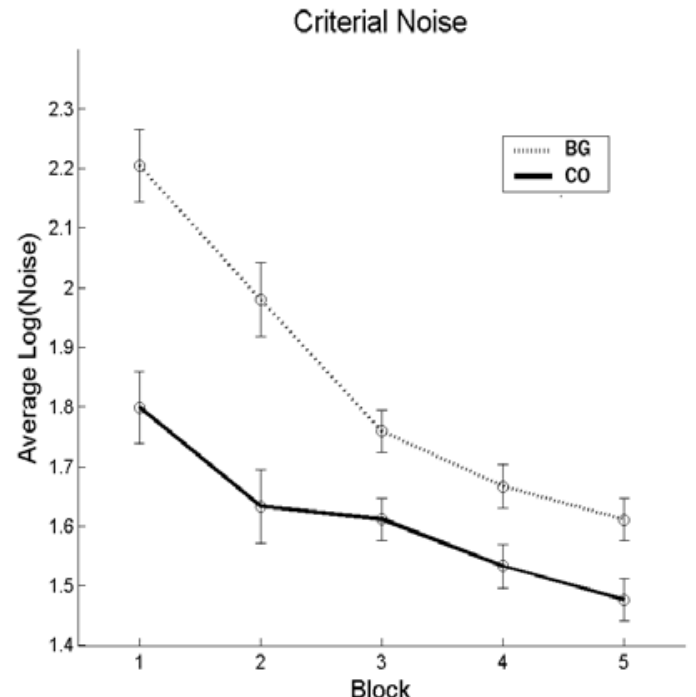

Figure 4. Average criterial noise estimates (+/SEM) from the optimal rule-based model. These data have been log transformed to correct for a positive skew in the sample distributions. BG basal ganglia patients; $\mathrm{CO}$ - control participants

responding. Thus, the modeling described in this section provides a formal vehicle to test hypotheses about the decision strategies used by participants, even though it has little to say about psychological process.

The percentage of data sets best accounted for by rule-based decision strategies in the rule-based and information-integration tasks is given in Table 4. As expected, the majority of participants in the rule-based task were best-fit by rule-based strategies and the majority of the participants in the information-integration task were best-fit by information-integration strategies. In addition, the average percent of responses accounted for by the best-fitting model is listed in Table 4. For the models investigated here, this statistic has a lower bound of 25\% (i.e., random responding) and an upper bound of $100 \%$. While it is clear that the models did not provide a perfect account of these data, on average, the best-fitting models accounted for a greater percentage of the responses than would be predicted by chance for both groups.
A comparison of basal ganglia and control groups in the rule-based task reveals no differences in the frequency of use of rulebased strategies [block 1: $\chi^{2}(1)=.38, p=.59$; block $2: \chi^{2}(1)=.38, p=.55$; block $3: \chi^{2}(1)=$ $.38, p=.59$; block 4: $\chi^{2}(1)=.38, p=.55$; block 5: $\left.\chi^{2}(1)=.85, p=1.0\right]^{3}$. Interestingly, in the information-integration task there was a consistent trend across blocks for basal ganglia patients to be less likely to use rulebased strategies (i.e., more likely to use information-integration strategies) than control participants. This difference, however, did not reach statistical significance in any block [block 1: $\chi^{2}(1)=.20, p=.31$; block 2: $\chi^{2}(1)=.84, p=1.0$; block 3: $\chi^{2}(1)=.20, p=$ .31 ; block 4: $\chi^{2}(1)=.09, p=.21$; block 5: $\chi^{2}$ $(1)=.20, p=.31]^{3}$. Nevertheless, the increased use of information-integration strategies by the basal ganglia patients may reflect a competitive process - an issue to which we return in the General Discussion.

While limited by the small sample size, it would appear that a qualitative difference in strategy cannot explain the impairment of the basal ganglia patients early in training on the rule-based task. Another possibility is that patients may have been attending selectively to either length or orientation when making categorization decisions. Such a unidimensional strategy is highly suboptimal when compared to the optimal strategy - i.e., a conjunction rule in which there is a single decision criterion on length and orientation (see Appendix). Comparing the number of participants using unidimensional strategies, however, reveals little difference between groups (basal ganglia patients: block $1-0 / 7$, block 2 - 1/7; control participants: block 1 $1 / 9$, block $2-3 / 9$ ). These data suggest that the impairment in the basal ganglia patients was not driven by the use of suboptimal, unidimensional decision strategies.

\footnotetext{
3 Fisher's exact test was used because there were fewer than five cases in at least one cell.
} 
A different source of the learning impairment for the patients may be increased trial-by-trial variability in the decision strategy (or criterial noise). Consistent with analyses performed in previous work (e.g., Maddox et al., 2005), we used the noise estimates from the optimal rule-based model as a measure of criterial noise (Figure 4$)^{4}$. Throughout the experiment, the patients exhibited increased criterial noise relative to controls. The greatest deficit, however, occurred during the blocks in which accuracy was also impaired. An analysis of the Figure 4 data showed a main effect of block $[F(4,56)=40.74, p<.001$, $\left.M S E=.01, \eta_{p}{ }^{2}=.74\right]$, but not group $[F(1,14)$ $\left.=2.50, p=.14, M S E=.43, \eta_{p}^{2} .15\right]$. However, there was a significant block $\mathrm{x}$ group interaction $[F(4,56)=5.32, p=.001, M S E=$ $\left..01, \eta_{p}^{2}=.28\right]$, driven by a significant difference in criterial noise during block 1 ( $p$ $=.02$ ) and a marginally significant difference during block $2(p=.07)$. None of the remaining pairwise comparisons were significant $(p>.14)^{5}$.

The finding of increased criterial noise for the basal ganglia patients has multiple interpretations. If the increased noise represented increased variability in the application of near-optimal decision strategies, then the error rates should be greatest for stimuli near the category boundaries. Such errors would likely reflect on-going tuning of this decision strategy. In contrast, increased noise could be driven by frequent shifts

\footnotetext{
4 All of the models investigated include a free parameter to reflect the combined trial-by-trial variability in perceptual and criterial noise (Ashby, 1992a). Given that the stimuli were displayed at high contrast and that the duration of stimulus presentation was unlimited, it is reasonable to assume that this internal noise primarily reflects variability in the decision criteria. Furthermore, the success of the basal ganglia patients in the information-integration task would also argue against a general perceptual deficit.

${ }^{5}$ A similar pattern of results was observed when analyzing the criterial noise estimates from the best-fitting rule-based model. Specifically, a significant block x group interaction $[F(4,56)=6.76$, $p=.001, M S E=.15, \eta_{p}{ }^{2}=.33$ ] driven by a marginally significant difference during block $2(p=.07)$ and a significant difference during block $3(p=.001)$.
}

between qualitatively different decision strategies. For example, within the initial block of 100 trials, participants may begin by using a highly suboptimal conjunction strategy (e.g., length intercept $=50$ pixels, orientation

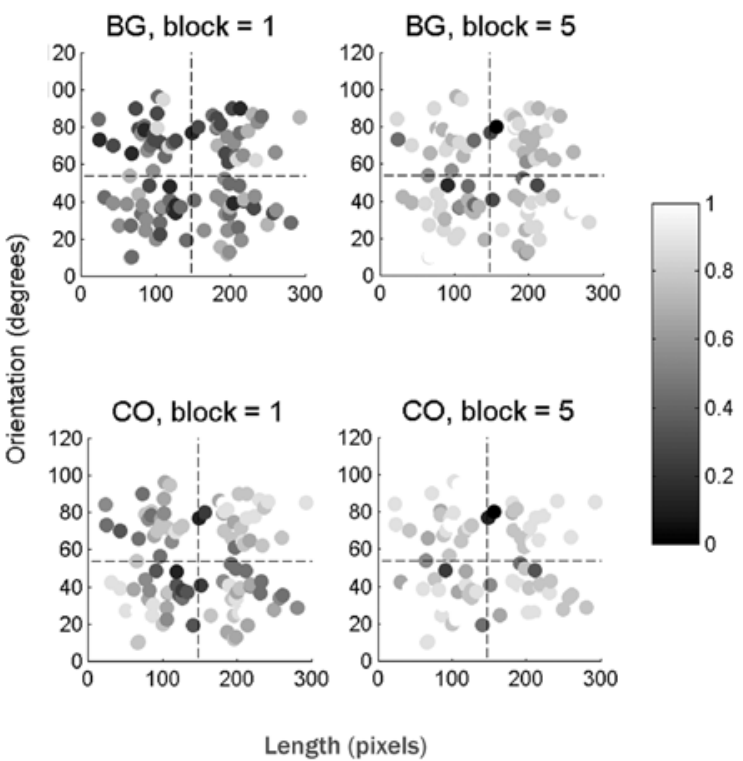

Figure 5. Probability of a correct response for each stimulus. The shading of each point represents the probability that the stimulus was correctly classified. Darker colors indicate stimuli with a lower probability of correct classification. The dashed lines are the optimal decision boundaries. BG - basal ganglia patients; CO control participants.

intercept $=80$ degrees). After several trials, they may switch to quite a different suboptimal strategy (e.g., length intercept = 250 pixels, orientation intercept $=20$ degrees), eventually settling on the optimal strategy (length intercept $=150$ pixels, orientation intercept $=54$ degrees). Such switches in decision strategy would predict that error rates would be distributed more uniformly in the length - orientation space.

Investigation of the distribution of errors in the stimulus space provides some insight into this question. The accuracy rate for each stimulus across blocks is plotted for the basal ganglia and control groups in Figure 5. The 
grayscale of each stimulus represents the proportion of correct responses (across participants) with darker shades of gray indicating more errors. The distribution of errors was quite broad for both groups on block 1, although the control data already indicate that the highest error rates are for stimuli near the category boundary. By the end of training, the distribution of errors in the two groups was indistinguishable with stimuli with the highest error rates being near the category boundary, suggesting refinement in the estimates of the decision criteria.

Although the inspection of the Figure 5 data supports the hypothesis that the increased criterial noise in the patient group was driven by large, frequent shifts in decision strategy, a quantitative analysis would be more compelling. Towards this goal, the correlation between the proportion of correct responses and the distance to the optimal decision strategy was computed across stimuli. If the increased noise represented increased variability in the application of near-optimal decision strategies, then this correlation should be large and positive. On the other hand, if the distribution of error data is driven by frequent shifts between qualitatively different decision strategies, as we have argued, this correlation should be close to zero. Indeed, this is what was observed for the basal ganglia patients in block 1 ( $r=.11, p=$ .29). By block 5, the correlation was significant, consistent with what would be expected if a near-optimal strategy was being employed, but with some inconsistency ( $r=$ $.54, p=.0001)$. The controls also showed an increase in the correlation over blocks, although the correlation was already reliable in the first block (block 1: $r=.39, p=0001$; block 5: $r=.56, p=0)^{6}$.

The above analysis suggests that the basal ganglia patients took longer than the control participants to stabilize their decision bounds. A different form of a decision-based suboptimality arises if participants prefer some category responses over others; that is, if there is are systematic biases even though the appropriate strategy is adopted. A fairly simple method to address the question of response bias is to compare the relative category response frequencies across the two groups (Maddox et al., 2005). A response bias statistic was computed by subtracting the number of responses given to the least preferred category from the number given to the most preferred category. This difference score was computed for each participant separately and the group averages are presented in Table 5. There was little difference between groups, suggesting that a response bias was not driving the impairment during blocks 1 and 2 . In fact, the only substantial group difference occurred during block 4.

Table 5.

Relative Response Frequencies in the RuleBased Task

\begin{tabular}{ccc}
\hline \multicolumn{3}{c}{ Basal Ganglia Patients } \\
Block & Mean & SEM \\
\hline 1 & 15.1 & 2.5 \\
2 & 13.9 & 1.8 \\
3 & 14.7 & 2.0 \\
4 & 14.3 & 2.7 \\
5 & 13.0 & 1.8 \\
& & \\
Block & Control Participants & \\
1 & Mean & SEM \\
2 & 13.1 & 1.6 \\
3 & 12.9 & 1.8 \\
4 & 12.6 & 1.5 \\
5 & 9.9 & 1.6 \\
\hline
\end{tabular}

\footnotetext{
${ }^{6}$ We are indebted to an anonymous reviewer for suggesting this analysis.
} 


\section{General Discussion}

Considerable evidence implicates the basal ganglia in category learning (Ashby, Noble et al., 2003; Filoteo, Maddox, Salmon et al., 2005; Knowlton et al., 1996; Poldrack et al., 2001; Price, 2005; Seger \& Cincotta, in press). Previous patient work, however, has relied on individuals with degenerative disorders of the basal ganglia such as Parkinson's and Huntington's disease. The present paper complements this work by testing the category learning ability of a group of patients with focal lesions of the basal ganglia. The results show that these individuals do not manifest a generic deficit in all category learning tasks. Instead, the basal ganglia patients were selectively impaired on the rule-based task and only during the first few hundred trials.

The model-based analyses reveal that the deficit in the rule-based task was not due to the use of qualitatively different decision strategies (i.e., information-integration strategies) in the basal ganglia and control groups. Instead, the patients were suboptimal in their use of rule-based decision strategies. Specifically, patients were more likely to make large shifts in their decision criteria during the initial phase of learning. Later in training, however, the patients were able to reach levels of performance comparable to the control participants by becoming more consistent in their use of rule-based strategies.

\section{Selective Impairment in Rule-Based Category} Learning

The bulk of previous research investigating the role of the basal ganglia in rule-based category learning has relied upon tasks where only a single dimension is relevant and participants must discover the relevant dimension while ignoring irrelevant dimensions in order to maximize accuracy. These types of rule-based tasks are difficult to compare with information-integration tasks given that, by definition, such tasks require the integration of information from multiple dimensions. Accordingly, we opted to use rule-based and information-integration tasks that required attending to two dimensions. We also selected tasks that were equated on task difficulty, optimal accuracy, and the statistical properties of the categories (i.e., within- and between-category discriminability). Thus, the selective impairment on the rule-based task cannot be attributed to methodological differences.

This finding may appear at odds, however, with related research demonstrating no impairment among Parkinson's patients in a multi-dimensional rule based task (Filoteo, Maddox, Ing, \& Song, 2005; Maddox \& Filoteo, 2001). Although it is possible that this discrepancy represents a difference in the nature of the pathology (i.e., dopamine depletion in the basal ganglia and/or frontal regions vs. lesions of the basal ganglia), a number of methodological differences make such a conclusion premature. For example, the rule-based task of Maddox and Filoteo (2001) required participants to directly compare two stimulus dimensions measured in the same units (i.e., line length) which may have resulted in the optimal decision strategy being conceptualized as a unidimensional strategy defined on the psychological dimension of relative line length. In contrast, the present task required participants to attend to two separable stimulus dimensions (i.e., line length and orientation).

The results of previous work investigating the ability of patients with degenerative disorders of the basal ganglia to learn information-integration tasks have been mixed (Ashby, Noble et al., 2003; Filoteo et al., 2001; Filoteo, Maddox, Salmon et al., 2005; Price, 2005). This inconsistency would seem to stem from the complexity of the optimal decision strategy, with patients being impaired when the decision strategy is sufficiently complex (Filoteo, Maddox, Salmon et al., 2005; Price, 2005). Strategy complexity has 
been a notoriously difficult concept to define and operationalize, and it may be that the patients in the present information-integration task were not impaired because the optimal strategy was not sufficiently complex. We acknowledge that given the small sample size it is difficult to draw strong conclusions based upon a null effect in the informationintegration task. However, it is also difficult to imagine that a realistic increase in sample size would result in impairment in the basal ganglia group given the almost nonexistent effect observed in the present data.

Other types of information-integration tasks have yielded inconsistent results with respect to the role of the basal ganglia in category learning. For instance, patients with basal ganglia dysfunction have been found to be impaired on the weather prediction task (e.g., Keri et al., 2002; Knowlton et al., 1996; Shohamy et al., 2004; Witt et al., 2002), a task in which probabilistic cue-outcome relationships must be integrated for optimal performance(Knowlton et al., 1994). Other studies using the weather prediction task, however, have failed to observe any deficits in similar patient groups (Moody, Bookheimer, Vanek, \& Knowlton, 2004; Price, 2005; Sage et al., 2003). It has been argued that this variability, at least for patients with Parkinson's disease, may be attributed to differences in disease severity (Moody et al., 2004) or, more specifically, the severity of executive dysfunction (Price, 2005).

\section{Multiple Systems in Category Learning}

It is important to interpret these data within the broader context of biologicallyplausible models of category learning (e.g., Ashby et al., 1998; Frank, 2005). The present data are particularly relevant to the COVIS (COmpetition between Verbal and Implicit Systems) model of category learning (Ashby et al., 1998). COVIS hypothesizes that category learning is a competition between an explicit, hypothesis-testing system and an implicit, procedural-based system. The hypothesis-testing system is thought to dominate learning in rule-based tasks whereas the procedural-based system is thought to dominate learning in information-integration tasks.

The two systems operate in parallel and compete for control of the observable categorization response, although this competition is biased in favor of the hypothesis-testing system. Therefore, a reasonable prediction would be that damage to the hypothesis-testing system (as indexed by impairment on a rule-based task) would result in an increase in the use of informationintegration strategies. In fact, such a trend, although nonsignificant, was observed in the information-integration task. The fact that this pattern was not observed in the rule-based task is not surprising given that the proceduralbased system is capable of learning rule-based tasks (Ashby et al., 1998). Thus, perhaps the procedural-based system was driving successful performance late in the rule-based task. Alternatively, it may be the case that the hypothesis-testing system was impaired, but this impairment was not severe enough for the procedural-based system to dominate responding in the rule-based task. Consistent with this assumption, previous efforts to disrupt learning in the hypothesis-testing system by increasing working memory load have resulted in a decrease in the relative dominance of the hypothesis-testing system rather than a shift in dominance to the procedural-based system (Ashby \& Ell, 2002).

According to COVIS, learning in rulebased tasks requires the maintenance of decision strategies in working memory, the selection of novel rules, and the ability to switch attention among competing rules (Ashby et al., 1998). In theory, lesions of the putamen may have interfered with any of these sub-processes. The increased criterial noise that was observed for the patients suggests, however, that the impairment in the 
rule-based task was driven by impaired maintenance or an increased propensity to switch attention from one rule to another. Although such a conclusion is speculative it is consistent with the hypothesized role of the basal ganglia in rule-based processing in a variety of other domains: e.g., working memory (Ashby, Ell, Valentin, \& Casale, 2005; Lawrence, Watkins, Sahakian, Hodges, \& Robbins, 2000), executive functioning (Cools, 2006; Crone, Wendelken, Donohue, \& Bunge, in press; Owen et al., 1993), and language use (Longworth, Keenan, Barker, Marslen-Wilson, \& Tyler, 2005; Teichmann et al., 2005; Ullman, 2004).

In COVIS, the hypothesis-testing and procedural-based systems are assumed to depend upon separate, yet partially overlapping, neural networks (see Ashby et al., 1998 for a review). Of particular relevance to the present study, the model posits that, within the basal ganglia, the head of the caudate nucleus is part of the hypothesistesting system. This assumption is consistent with the results from a number of studies (e.g., Filoteo, Maddox, Simmons et al., 2005; Hikosaka, Sakamoto, \& Sadanari, 1989; Rao, 1997; Seger \& Cincotta, in press). The present finding showing that lesions of the putamen selectively impair learning in rule-based tasks would appear to be odds with this aspect of COVIS. The critical test, however, would require patients with lesions encompassing the caudate. Moreover, Ashby and colleagues (Ashby et al., 1998) acknowledge that ventralposterior portions of the putamen may also be involved in category learning and, furthermore, that the putamen may be involved in resolving competition between the hypothesis-testing and procedural-based systems.

A variety of data support a role for the putamen in rule-based tasks. For example, the firing rate of cells in the putamen predicts category membership in a rule-based categorization task using tactile stimuli
(Merchant, Zainos, Hernandez, Salinas, \& Romo, 1997). Putamen activity has also been correlated with feedback processing in rulebased tasks (Monchi, Petrides, Petre, Worsley, \& Dagher, 2001; Seger \& Cincotta, in press), perhaps reflecting the switching of attention among competing rules. In addition, the reduction in neostriatal (caudate and putamen) dopamine levels in patients with Parkinson's disease has been shown to result in impaired learning in rule-based tasks (Ashby, Noble et al., 2003; Brown \& Marsden, 1988; Maddox et al., 2005).

The exact role of the putamen in rulebased tasks is unclear. One possibility is that the putamen may be affecting processing within the caudate nucleus via striatal cell bridges (Martin, 1996) or other local networks within the basal ganglia (e.g., striato-nigralstriatal projections) (Haber, 2003). The putamen also receives input from prefrontal cortical structures thought to be important in rule-based category learning (Selemon \& Goldman-Rakic, 1985, 1988). As might be expected if the impairment in the rule-based task were related to disruption of processing in prefrontal regions, the patients demonstrated deficits in some of the neuropsychological tests designed to assess working memory and executive functioning. There was also a sizeable, but non-significant correlation between working memory measures and accuracy during the blocks in which the basal ganglia patients were impaired. This argument, however, is indirect and limited by the small sample size. Future work is needed in patients with prefrontal damage to more directly address this issue.

It is important to keep in mind that for all of the patients, the lesions were restricted to one hemisphere. We cannot rule out the possibility that unilateral basal ganglia damage produced a subtle deficit in the information-integration task that would be revealed following bilateral damage. Furthermore, because only one of the patients 
had damage in the right hemisphere, asymmetrical functions of the left and right basal ganglia in rule-based and informationintegration tasks remains unclear. Our understanding of the functional contribution to category learning of the various basal ganglia nuclei of both hemispheres would, of course, benefit from testing with a wider range of patient groups. The current data represent an important initial step in relating the structure of the basal ganglia to function.

\section{Conclusions}

Patients with lesions of the putamen were selectively impaired on a rule-based categorization task during the first few hundred trials. The impairment was driven by an increased tendency for the patients to make large, suboptimal shifts in their decision strategy. It is important to note that these data do not directly address the involvement of other neural structures in category learning (i.e., prefrontal cortex, caudate nucleus, medial temporal lobes). Instead, these data argue for a greater consideration of the putamen in theories of rule-based category learning (e.g., the hypothesis-testing system of COVIS) and cognitive functioning in general.

Author Notes This research was supported by grants NS047884, NS30256, and NS40813 from the National Institutes of Health. The authors would like to thank Donatella Scabini and Leslie Shupenko for their assistance in the recruitment and assessment of the patients. Thanks to Andrea Weinstein for assistance with data collection and to Matthew Brett and Mark D'Esposito for their assistance with the analysis of the MRI scans. Neil Albert, Greg Ashby, Matthew Brett, Roshan Cools, Vince Filoteo, and Todd Maddox provided helpful discussions of these data. We would also like to thank Shannon McCoy and three anonymous reviewers for providing helpful comments on an earlier version of this manuscript. Correspondence concerning this article should be addressed to Shawn W. Ell, Cognition \& Action Lab, Helen Wills Neuroscience Institute \& Psychology Department, University of California, 3210 Tolman Hall \#1650, Berkeley, CA 947201650 shawnell@socrates.berkeley.edu).

\section{References}

Alfonso-Reese, L. A. (1997). On the dangers of ignoring noise in high-level perception experiments. Unpublished Manuscript: Indiana University.

Aparicio, P., Diedrichsen, J., \& Ivry, R. B. (2005). Effects of focal basal ganglia lesions on timing and force control. Brain and Cognition, 58, 62-74.

Ashby, F. G. (1992a). Multidimensional models of categorization. In F. G. Ashby (Ed.), Multidimensional models of perception and cognition. Hillsdale, NJ: Erlbaum.

Ashby, F. G. (1992b). Multivariate probability distributions. In F. G. Ashby (Ed.), Multidimensional models of perception and cognition (pp. 1-34). Hillsdale: Lawrence Erlbaum Associates, Inc.

Ashby, F. G., Alfonso-Reese, L. A., Turken, A. U., \& Waldron, E. M. (1998). A neuropsychological theory of multiple systems in category learning. Psychological Review, 105, 442-481.

Ashby, F. G., \& Ell, S. W. (2001). The neurobiology of human category learning. Trends in Cognitive Science, 5(5), 204-210.

Ashby, F. G., \& Ell, S. W. (2002). Single versus multiple systems of category learning: Reply to Nosofsky and Kruschke (2002). Psychonomic Bulletin \& Review, 9, 175-180. 
Ashby, F. G., Ell, S. W., Valentin, V. V., \& Casale, M. B. (2005). FROST: A distributed neurocomputational model of working memory maintenance. Journal of Cognitive Neuroscience, 17, 1728-1743.

Ashby, F. G., Ell, S. W., \& Waldron, E. M. (2003). Procedural learning in perceptual categorization. Memory \& Cognition, 31, 1114-1125.

Ashby, F. G., \& Gott, R. E. (1988). Decision rules in the perception and categorization of multidimensional stimuli. Journal of Experimental Psychology: Learning, Memory, and Cognition, 14, 33-53.

Ashby, F. G., \& Lee, W. W. (1993). Perceptual variability as a fundamental axiom of perceptual science. In S. C. Masin (Ed.), Foundations of percpetual theory (pp. 369-399). Amsterdam: Elsevier.

Ashby, F. G., \& Maddox, W. T. (2005). Human category learning. Annual Review of Psychology, 56, 149-178.

Ashby, F. G., Maddox, W. T., \& Bohil, C. J. (2002). Observational versus feedback training in rule-based and informationintegration category learning. Memory \& Cognition, 30, 666-677.

Ashby, F. G., Noble, S., Filoteo, J. V., Waldron, E. M., \& Ell, S. W. (2003). Category Learning Deficits in Parkinson's Disease. Neuropsychology, 17, 115-124.

Ashby, F. G., \& Spiering, B. J. (2004). The neurobiology of category learning. Behavior and Cognitive Neuroscience Reviews, 3, 101-113.

Ashby, F. G., \& Townsend, J. T. (1986). Varieties of perceptual independence. Psychological Review, 93, 154-179.

Ashby, F. G., \& Waldron, E. M. (1999). The nature of implicit categorization. Psychonomic Bulletin \& Review, 6, 363-378.
Ashby, F. G., Waldron, E. M., Lee, W. W., \& Berkman, A. (2001). Suboptimality in human categorization and identification. Journal of Experimental Psychology: General, 130(77-96).

Beck, A. T., Steer, R., \& Brown, G. (1996). Beck Depression Inventory - Second edition manual. San Antonio, TX: Psychological Corporation.

Brainard, D. H. (1997). Psychophysics software for use with MATLAB. Spatial Vision, 10, 433-436.

Brett, M., Leff, A. P., Rorden, C., \& Ashburner, J. (2001). Spatial normalization of brain images with focal lesions using cost function masking. Neuroimage, 14, 486-500.

Brown, J., Bullock, D., \& Grossberg, S. (1999). How the basal ganglia use parallel excitatory and inhibitory learning pathways to selectively respond to unexpected rewarding cues. Journal of Neuroscience, 19, 1050210511.

Brown, R. G., \& Marsden, C. D. (1988). Internal versus external cures and the control of attention in Parkinson's disease. Brain, 111, 323-345.

Bunge, S. A. (2004). How we use rules to select actions: A review of evidence from cognitive neuroscience. Cognitive, Affective, \& Behavioral Neuroscience, 4, 564-579.

Cools, A. R., van den Bercken, J. H. L., Horstink, M. W. I., van Spaendonck, K. P. M., \& Berger, H. J. C. (1984). Cognitive and motor shifting aptitude disorder in Parkinson's disease. Journal of Neurology, Neurosurgery and Psychiatry, 47, 443-453.

Cools, R. (2006). Dopaminergic modulation of cognitive function: implications for L-DOPA treatment in Parkinson's disease. Neuroscience and Biobehavioral Reviews, 30, 1-23. 
Crone, E. A., Wendelken, C., Donohue, S. E., \& Bunge, S. A. (in press). Neural evidence for dissociable components of task-switching. Cerebral Cortex.

Delis, D. C., Kaplan, E., \& Kramer, J. H. (2001). Delis-Kaplan Executive Functioning System. San Antonio, TX: The Psychological Corporation.

Delis, D. C., Kramer, J. H., Kaplan, E., \& Ober, B. A. (1984). California Verbal Learning Test. San Antonio: Psychological Corporation.

Downes, J. J., Roberts, A. C., Sahakian, B. J., Evenden, J. L., Morris, R. G., \& Robbins, T. W. (1989). Impaired extradimensional shift performance in medicated and unmedicated Parkinson's disease: Evidence for a specific attentional dysfunction. Neuropsychologia, 27, 1329-1343.

Ell, S. W., \& Ashby, F. G. (in press). The effects of category overlap on information-integration and rule-based category learning. Perception and Psychophysics.

Ell, S. W., \& Ivry, R. B. (2005). [Patients with cerebellar degeneration are not impaired in rule-based or informationintegration category learning]. Unpublished raw data.

Filoteo, J. V., Maddox, W. T., \& Davis, J. D. (2001). A possible role of the striatum in linear and nonlinear categorization rule learning: Evidence from patients with Huntington's disease. Behavioral Neuroscience, 115, 786-798.

Filoteo, J. V., Maddox, W. T., Ing, A. D., \& Song, D. D. (2005). Characterizing rule-based category learning deficits in patients with Parkinson's disease. Manuscript submitted for publication.

Filoteo, J. V., Maddox, W. T., Ing, A. D., Zizak, V., \& Song, D. D. (2005). The impact of irrelevant dimensional variation on rule-based category learning in patients with Parkinson's disease. Journal of the International Neuropsychological Society, 11, 503513.

Filoteo, J. V., Maddox, W. T., Salmon, D. P., \& Song, D. D. (2005). Informationintegration category learning in patients with striatal dysfunction. Neuropsychology, 19, 212-222.

Filoteo, J. V., Maddox, W. T., Simmons, A. N., Ing, A. D., Cagigas, X. E., Matthews, S., et al. (2005). Cortical and subcortical brain regions involved in rule-based category learning. NeuroReport, 16, 111-115.

Frank, M. J. (2005). Dynamic dopamine modulation in the basal ganglia:A neurocomputational account of cognitive deficits in medicated and non-medicated Parkinsonism. Journal of Cognitive Neuroscience, 17, 51-72.

Garner, W. R. (1974). The processing of information and structure. New York: Wiley.

Gluck, M. A., Shohamy, D., \& Myers, C. (2002). How do people solve the "weather prediction" task?: individual variability in strategies for probabilistic category learning. Learning \& Memory, 9, 408-418.

Green, D. M., \& Swets, J. A. (1966). Signal detection theory and psychophysics. New York: Wiley.

Haber, S. N. (2003). The primate basal ganglia: parallel and integrative networks. Journal of Chemical Neuroanatomy, 26, 317-330.

Hikosaka, O., Sakamoto, M., \& Sadanari, U. (1989). Functional properties of monkey caudate neurons III. Activities related to expectation of target and reward. Journal of Neurophysiology, 61, 814-831.

Kemler Nelson, D. G. (1993). Processing integral dimensions: The whole view. Journal of Experimental Psychology: 
Human Perception \& Performance, 19, 1105-1113.

Keri, S. (2003). The cognitive neuroscience of category learning. Brain Research Reviews, 43, 85-109.

Keri, S., Beniczky, S., Voros, E., Janka, Z., Benedek, G., \& Vecsei, L. (2002). Dissociation between attentional set shifting and habit learning: a longitudinal case study. Neurocase, 8 , 219-225.

Knowlton, B. J., Mangels, J. A., \& Squire, L. R. (1996). A neostriatal habit learning system in humans. Science, 273, 13991402.

Knowlton, B. J., Squire, L. R., \& Gluck, M. A. (1994). Probabilistic classification learning in amnesia. Learning and Memory, 1, 106-120.

Lawrence, A. D., Watkins, L. H. A., Sahakian, B. J., Hodges, J. R., \& Robbins, T. W. (2000). Visual object and visuospatial cognition in Huntington's disease: implications for information processing in corticostriatal circuits. Brain, 123, 1349-1364.

Longworth, C. E., Keenan, S. E., Barker, R. A., Marslen-Wilson, W. D., \& Tyler, L. K. (2005). The basal ganglia and rule-governed language use: evidence from vascular and degenerative conditions. Brain, 128, 584-596.

Maddox, W. T., Aparicio, P., Marchant, N. L., \& Ivry, R. B. (2005). Rule-based category learning is impaired in patients with Parkinson's Disease but not patients with cerebellar disorders. Journal of Cognitive Neuroscience, 17, 707-723.

Maddox, W. T., \& Ashby, F. G. (1993).

Comparing decision bound and exemplar models of categorization. Perception \& Psychophysics, 53, 4970.

Maddox, W. T., \& Ashby, F. G. (2004). Dissociating Explicit and Procedural-
Learning Based Systems of Perceptual

Category Learning. Behavioral

Processes, 66, 309-332.

Maddox, W. T., Ashby, F. G., \& Bohil, C. J. (2003). Delayed feedback effects on rule-based and information-integration category learning. Journal of Experimental Psychology: Learning, Memory, and Cognition, 29, 650-662.

Maddox, W. T., Bohil, C. J., \& Ing, A. D. (2004). Evidence for a procedural learning-based system in perceptual category learning. Psychonomic Bulletin \& Review, 11, 945-952.

Maddox, W. T., \& Filoteo, J. V. (2001). Striatal contribution to category learning: Quantitative modeling of simple linear and complex non-linear rule learning in patients with Parkinson's disease. Journal of the International Neuropsychological Society, 7, 710-727.

Maddox, W. T., Filoteo, J. V., Hejl, K. D., \& Ing, A. D. (2004). Category Number Impacts Rule-Based but not Information-Integration Category Learning: Further Evidence for Dissociable Category Learning Systems. Journal of Experimental Psychology: Learning, Memory, and Cognition, 30, 227-235.

Martin, J. H. (1996). Neuroanatomy: Text and atlas (2nd ed.). Stamford, CT: Appleton \& Lange.

Merchant, H., Zainos, A., Hernandez, A., Salinas, E., \& Romo, R. (1997). Functional properties of primate putamen neurons during the categorization of tactile stimuli. Journal of Neurophysiology, 77, 11321154.

Monchi, O., Petrides, M., Petre, V., Worsley, K., \& Dagher, A. (2001). Wisconsin Card Sorting Revised: Distinct Neural Circuits Participating in Different Stages of the Task Identified by Event- 
Related Functional Magnetic Resonance Imaging. The Journal of Neuroscience, 21, 7733-7741.

Moody, T. D., Bookheimer, S. Y., Vanek, Z., \& Knowlton, B. J. (2004). An implicit learning task activates medial temporal lobe in patients with Parkinson's disease. Behavioral Neuroscience, $118,438-442$.

Nomura, E. M., Maddox, W. T., Filoteo, J. V., Ing, A. D., Gitelman, D. R., Parrish, T. B., et al. (in press). Neural correlates of rule-based and informationintegration visual category learning. Cerebral Cortex.

Owen, A. M., Roberts, A. C., Hodges, J. R., Summers, B. A., Polkey, C. E., \& Robbins, T. W. (1993). Contrasting mechanisms of impaired attentional set-shifting in patients with frontal lobe damage or Parkinsons's disease. Brain, 116, 1159-1175.

Pelli, D. G. (1997). The VideoToolbox software for visual psychophysics: Transforming numbers into movies. Spatial Vision, 10, 437-442.

Poldrack, R. A., Clark, J., Pare-Blagoev, E. J., Shohamy, D., Moyano, J. C., Myers, C., et al. (2001). Interactive memory systems in the human brain. Nature, $414,546-550$.

Price, A. L. (2005). Cortico-striatal contributions to category learning: Dissociating the verbal and implicit systems. Behavioral Neuroscience, 119, 1438-1447.

Rao, S. M., Bobholz, J. A., Hammeke, T. A., Rosen, A. C., Woodley, S. J., Cunningham, J. M., Cox, R. W., Stein, E. A., \& Binder, J. R. (1997). Functional MRI evidence for subcortical participation in conceptual reasoning skills. Neuroreport, 27, 1987-1993.
Rorden, C., \& Brett, M. (2000). Stereotaxic display of brain lesions. Behavioural Neurology, 12, 191-200.

Sage, J. R., Anagnostaras, S. G., Mitchell, S., Bronstein, J. M., De Salles, A., Masterman, D., et al. (2003). Analysis of probabilistic classification learning in patients with Parkinson's disease before and after pallidotomy surgery. Learning \& Memory, 10, 226-236.

Salatas, H., \& Bourne, L. E. (1974). Learning Conceptual Rules III: Processes contributing to rule difficulty. Memory \& Cognition, 2, 549-553.

Schwarz, G. (1978). Estimating the dimension of a model. The Annals of Statistics, 6(2), 461-464.

Seger, C. A., \& Cincotta, C. M. (2002). Striatal activity in concept learning. Cognitive, Affective, \& Behavioral Neuroscience, 2, 149-161.

Seger, C. A., \& Cincotta, C. M. (in press). Dynamics of frontal, striatal, and hippocampal systems during rule learning. Cerebral Cortex.

Selemon, L. D., \& Goldman-Rakic, P. S. (1985). Longitudinal topography and interdigitation of cortico-striatal projections in the rhesus monkey. Journal of Neuroscience, 5, 776-794.

Selemon, L. D., \& Goldman-Rakic, P. S. (1988). Common cortical and subcortical targets of the dorsolateral prefrontal and posterior parietal cortices in the rhesus monkey: evidence for a distributed neural network subserving spatially guided behavior. Journal of Neuroscience, 8 , 4049-4068.

Shaw, M. L. (1982). Identifying attentional and decision-making components in information processing. In R. S. Nickerson (Ed.), Attention and Performance (Vol. 8). Hillsdale: Erlbaum. 
Shepard, R. N., Hovland, C. I., \& Jenkins, H. M. (1961). Learning and memorization of classifications. Psychological Monographs, 75, 42.

Shohamy, D., Myers, C. E., Onlaor, S., \& Gluck, M. A. (2004). Role of the basal ganglia in category learning: How do patients with Parkinson's disease learn? Behavioral Neuroscience, 118, 676-686.

Teichmann, M., Dupoux, E., Kouider, S., Brugieres, P., Boisse, M. F., Baudic, S., et al. (2005). The role of the striatum in rule application: the model of Huntington's disease at early stage. Brain, 128, 1155-1167.

Troyer, A. K., Black, S. E., Armilio, M. L., \& Moscovitch, M. (2004). Cognitive and motor functioning in a patient with selective infarction of the left basal ganglia: evidence for decreased nonroutine response selection and performance. Neuropsychologia, 42, 902-911.

Ullman, M. T. (2004). Contributions of memory circuits to language: the declarative/procedural model. Cognition, 92, 231-270.

Waldron, E. M., \& Ashby, F. G. (2001). The effects of concurrent task interference on category learning: Evidence for multiple category learning systems. Psychonomic Bulletin \& Review, 8, 168-176.

Wechsler, D. (1997). WAIS-III. Administration and Scoring Manual. San Antonio, TX: The Psychological Corporation.

Wickens, T. D. (1982). Models for behavior: Stochastic processes in psychology. San Francisco: W. H. Freeman.

Witt, K., Nuhsman, A., \& Deuschl, G. (2002). Dissociation of habit-learning in Parkinson's and cerebellar disease. Journal of Cognitive Neuroscience, 14, 493-499.
Zeithamova, D., \& Maddox, W. T. (in press). Dual task interference in perceptual category learning. Memory and Cognition.

\section{Appendix}

This appendix briefly describes the decision bound models. For more details, see Ashby (1992a) or Maddox and Ashby (1993). The classification of these models as either rule-based or information-integration models is designed to reflect current theories of how these strategies are learned (e.g., Ashby et al., 1998) and has received considerable empirical support (see Ashby \& Maddox, 2005; Maddox \& Ashby, 2004 for reviews).

\section{Rule-Based Models}

\section{Unidimensional Models.}

This model assumes that the length $\mathrm{x}$ orientation space is partitioned into four regions by setting three criteria on length or orientation. Two versions of the unidimensional model were fit to these data: one assumed that participants attended selectively to length and the other assumed participants attended selectively to orientation. The unidimensional models have four free parameters: three decision criteria on the relevant perceptual dimension and the variance of internal (perceptual and criterial) noise $\left(\sigma^{2}\right)$.

Conjunction models. A more appropriate rulebased strategy given the current stimulus configuration is a conjunction rule involving separate decisions about the stimulus value on the two dimensions with the response assignment based on the outcome of these two decisions. All conjunction models assume the participant partitions the length $\mathrm{x}$ orientation space into four regions in a manner consistent 
with the optimal decision strategy (see Figure 1).

Based upon inspection of the data from the individual participants, four different conjunction models varying in flexibility were investigated. The optimal rule-based model assumes that the participant uses the optimal decision criteria and has one free parameter $\left(\sigma^{2}\right)$. The remaining conjunction models were generalizations of the optimal model and assumed that either the length criterion, the orientation criterion, or both criteria were free to vary.

Conjunction $^{+}$models. This class of models is similar to the conjunction models with the exception that they assume two criteria on either the length or orientation dimensions. The first model assumes that the length dimension is partitioned into three regions and that an orientation criterion is used for stimuli intermediate in length resulting in the following rule: Respond 1 if the line is short; Respond 4 if the line is long; Respond 3 if the line is intermediate in length and shallow; Respond 2 if the line is intermediate in length and steep. A similar model assumes that the orientation dimension is partitioned into three regions and that a length criterion is used for stimuli intermediate in orientation (i.e., a 90 degree rotation of the first model) resulting in the following rule: Respond 1 if the line is intermediate in orientation and short; Respond 4 if the line is shallow; Respond 3 if the line is intermediate in orientation and long; Respond 2 if the line is steep. The models have four free parameters (two criteria on length/orientation, one criterion on orientation/length, and $\sigma^{2}$ ). Two additional models were simply generalizations where it was assumed that the two length or two orientation criteria were free to vary.

The final model assumes that the length dimension is partitioned into three regions and that an orientation criterion is used only for relatively long stimuli. This model assumes the participant uses the following rule: Respond 1 if the line is short, Respond 2 if the line is intermediate in length, Respond 3 if the line is long and steep, Respond 4 if the line is long and shallow. This model has four free parameters (two criteria on length, one criterion on orientation, and $\sigma^{2}$ ).

\section{Information-Integration Models}

The General Linear Classifier (GLC). This model assumes that two linear decision bounds partition the length $\mathrm{x}$ orientation space into four regions. The GLC differs from the conjunction models in that the decision bounds are not constrained to be orthogonal to the axes of the physical dimensions - i.e., the GLC does not assume decisional selective attention (Ashby \& Townsend, 1986). This produces an information-integration decision strategy because it requires linear integration of perceived length and orientation. The GLC has five parameters (the slope and intercept of the two linear bounds and a common noise parameter, $\sigma^{2}$ ). In the information-integration task, a special case of the GLC assumes participants use the linear bound that maximizes accuracy (i.e., the diagonal bounds shown in Figure 1). This optimal model has only one free parameter $\left(\sigma^{2}\right)$.

The Minimum Distance Classifier (MDC). This model assumes that the participant constructs four decision bounds to partition the length $\mathrm{x}$ orientation space into four response regions. An equivalent, and computationally simple, approach is to assume that there are four units in the lengthorientation space (Ashby \& Waldron, 1999; Ashby, Waldron, Lee, \& Berkman, 2001; Maddox, Filoteo et al., 2004). On each trial, the participant determines which unit is closest to the perceived stimulus and produces the associated response. Because the location of one of the units can be fixed, and because a uniform expansion or contraction of the space 
will not affect the location of the minimumdistance decision bounds, the MDC has six free parameters (five determining the location of the units and $\sigma^{2}$ ).

\section{Model Fitting}

The model parameters were estimated using maximum likelihood (Ashby, 1992b; Wickens, 1982) and the goodness-of-fit statistic was BIC $=r \ln N-2 \ln L$, where $N$ is the sample size, $r$ is the number of free parameters, and $L$ is the likelihood of the model given the data (Schwarz, 1978). The BIC statistic penalizes a model for poor fit and for extra free parameters. To find the best model among a set of competitors, one simply computes a BIC value for each model, and then chooses the model with the smallest BIC. 